\title{
Article \\ Genomic Regions and Candidate Genes Linked to Capped Hock in Pig
}

\author{
Lyubov Getmantseva ${ }^{1, *}$, Maria Kolosova ${ }^{1,2}$, Faridun Bakoev ${ }^{1}$, Anna Zimina ${ }^{1, *}$ and Siroj Bakoev ${ }^{1,3}$ \\ 1 Federal Research Center for Animal Husbandry Named after Academy Member L.K. Ernst, \\ 142132 Dubrovitsy, Russia; m.leonovaa@mail.ru (M.K.); bakoevfaridun@yandex.ru (F.B.); \\ siroj1@yandex.ru (S.B.) \\ 2 Department of Biotechnology, Don State Agrarian University, 346493 Persianovski, Russia \\ 3 Centre for Strategic Planning and Management of Biomedical Health Risks, 123182 Moscow, Russia \\ * Correspondence: ilonaluba@mail.ru (L.G.); filipchenko-90@mail.ru (A.Z.); \\ Tel.: +7-(4967)-65-11-01 (L.G. \& A.Z.)
}

Citation: Getmantseva, L.; Kolosova, M.; Bakoev, F.; Zimina, A.; Bakoev, S. Genomic Regions and Candidate Genes Linked to Capped Hock in Pig. Life 2021, 11, 510. https:/ / doi.org/ $10.3390 /$ life11060510

Academic Editors: Yuriy

Lvovich Orlov and Anastasia

A. Anashkina

Received: 22 April 2021

Accepted: 28 May 2021

Published: 31 May 2021

Publisher's Note: MDPI stays neutral with regard to jurisdictional claims in published maps and institutional affiliations.

Copyright: (c) 2021 by the authors. Licensee MDPI, Basel, Switzerland. This article is an open access article distributed under the terms and conditions of the Creative Commons Attribution (CC BY) license (https:// creativecommons.org/licenses/by/ $4.0 /)$.

\begin{abstract}
Capped hock affects the exterior of pedigree pigs, making them unsalable and resulting in a negative impact on the efficiency of pig-breeding centers. The purpose of this paper was to carry out pilot studies aimed at finding genomic regions and genes linked to the capped hock in pigs. The studies were carried out on Landrace pigs $(n=75)$ and Duroc pigs $(n=70)$. To identify genomic regions linked to capped hock in pigs, we used smoothing FST statistics. Genotyping was performed with GeneSeek ${ }^{\circledR}$ GGP Porcine HD Genomic Profiler v1 (Illumina Inc, San Diego, CA, USA). The research results showed 70 SNPs linked to capped hock in Landrace (38 SNPs) and Duroc (32 SNPs). The identified regions overlapped with QTLs related with health traits (blood parameters) and meat and carcass traits (fatness). In total, 31 genes were identified (i.e., 17 genes in Landrace, 14 genes in Durocs). Three genes appeared in both the Landrace and Duroc groups, including A2ML1 (SSC5), ROBO2 (SSC13), and MSI1 (SSC14). We identified genomic regions directly or indirectly linked to capped hock, which thus might contribute to identifying genetic variants and using them as genetic markers in pig breeding.
\end{abstract}

Keywords: pig; capped hock; selection signatures; genome; candidate genes; A2ML1; ROBO2; MSI1

\section{Introduction}

Limb diseases and specifically limb weakness (osteochondrosis) in pigs can lead to large economic losses due to a decrease in productivity [1-5]. Moreover, one of the serious problems facing pig farmers is the spread of bursitis of the hock and capped hock [6-8]. Bursitis of the hock usually occurs beneath the hock of the hind limb; it is less common in the forelimb. The capped hock is considered to be similar to the hock joint lesion, and therefore studies of capped hock and bursitis of the hock are commonly combined [6]. Capped hock is usually only a defect and does not lead to lameness, but this greatly affects the exterior of breeding pigs. This is because capped hock makes them unsalable, which has an extremely negative effect on the efficiency of pig breeding centers. We can consider production technology and genetics as predisposing factors of capped hock etiology. Revealing genome regions directly or indirectly linked to the capped hock problem may help identify genetic variants and use them as genetic markers in the selection of pig breeding stock. One approach for finding candidate genes that can become selectively valuable traits in farm animals is to identify selection signatures [9]. The discovery of selection signatures and the identification of candidate genes can identify the main genes responsible for the selected traits. The advantage of this approach is that it does not depend on the phenotype information for individual animals. Moreover, it is applicable to relatively small populations [10]. Therefore, we decided to apply the selection signatures approach to find genomic regions and genes linked to pigs' capped hock. 


\section{Materials and Methods}

In this study, we did not implement anesthesia or euthanasia, nor was any animal sacrificed. Further, this study did not involve any endangered or protected species. According to the standard monitoring procedures and guidelines, the participating holding specialists collected tissue samples following the ethical protocols outlined in the Directive 2010/63/EU (2010). The samples of pig ears (ear pluck) were obtained as a general monitoring procedure, as it is a standard practice in pig breeding [11].

The studies were carried out on Landrace pigs $(n=75)$ and Duroc pigs $(n=70)$ born in 2020. We chose Landrace and Duroc pigs because although they have different performance traits, they are both subject to capped hock. All pigs on the farm were raised under the same conditions, i.e., on concrete slotted floors. The animals were evaluated when they reached a weight of 100-110 kg (via visual inspection). The pigs were divided into two groups depending on the condition of their limbs. For groups I and II, the presence/absence of bumps in the hock region on the hind limbs of the pigs were inspected. Group I included Landrace $(\mathrm{n}=37)$ and Duroc $(\mathrm{n}=30)$, whereas group II included Landrace $(n=38)$ and Duroc $(n=40)$. To study population structure, we performed a singular value decomposition (SVD) of the GRM in R [12,13]. Figure 1 shows the SVD analysis. Predefined breed groups (Landrace and Duroc) corresponded to well-separated clusters. No outliers were apparent on the SVD plot and no stratification of pigs with or without capped hock was detected.

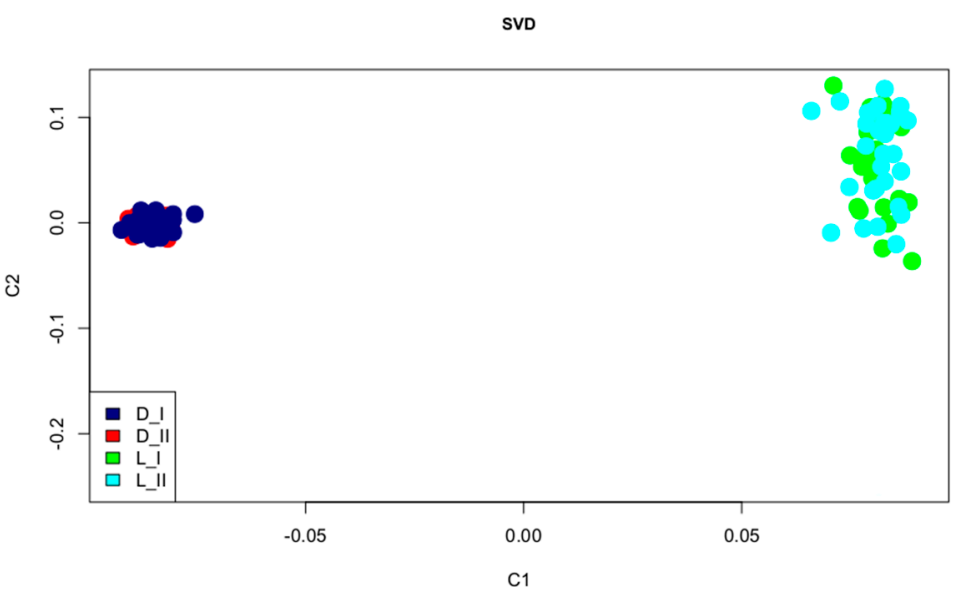

Figure 1. SVD plot.

To determine selection signatures, we used the FST smoothing approach by comparing pigs (group I vs. group II)) in accordance with breed (Landrace (L_I vs. L_II) and Duroc (D_I vs. D_II)).

\subsection{Genotyping}

Genomic DNA was extracted from ear samples using a DNA-Extran-2 reagent kit (OOO NPF Sintol, Russia) following the manufacturer's protocol. The quantity, quality, and integrity of DNA were assessed using a Qubit 2.0 fluorometer (Invitrogen/Life Technologies, Carlsbad, CA, USA) and a NanoDrop8000 spectrophotometer (ThermoFisher Scientific, Waltham, MA, USA). The samples were genotyped using the GeneSeek ${ }^{\circledR}$ GGP Porcine HD Genomic Profiler v1 (Illumina Inc., San Diego, CA, USA), which includes 68,516 SNPs evenly distributed genes with an average spacing of $25 \mathrm{~kb}$. Genotype quality control and data filtering were performed using PLINK 1.9. After excluding SNPs with a missing sample frequency of $>2 \%$, a Hardy-Weinberg equilibrium (HWE) $p$-value $<1 \times 10^{-7}$, rel-cutoff 0.75 , and LD pruned (50 5 0.2) 43,118 SNPs for Landrace pigs and 42,256 SNPs for Duroc pigs were retained for further analysis. 


\subsection{Data Processing}

To study population structure, we performed a singular value decomposition (SVD) decomposition of the GRM using the SVD function in R [12,13] (Figure S1). To determine selection signatures we used smoothing FST statistics based on the proposed model with pure drift [14]. Individual SNP FST values were grouped into genomic windows (contiguous regions) to determine smoothed FST values that could identify genomic regions with high FST values. FST was performed by comparing pigs L_I vs. L_II and D_I vs. D_II. SNP regions with smoothed FST values above the 99th quantile were identified. Further, the gene and QTL content of each region was analyzed in the Ensembl genome browser (Sscrofa 11.1) (https:/ / www.ensembl.org/index.html) (assessed on 28 May 2021). For every identified gene, we performed the PANTHER (http:/ / www.pantherdb.org/) (assessed on 28 May 2021). enrichment analysis using the Fisher's exact false detection rate adjustment (FDR) test. Moreover, we conducted a manual literature search for data on their associations with any traits in humans and animals.

\section{Results}

Using the smoothing FST method in pigs L_I vs. L_II, we found genome regions with strong outliers, which were comprised of 38 SNPs (Table S1 in Supplementary Materials). These regions overlapped with QTLs1 $(n=147)$, which represent traits related with health traits (109 QTLs-blood parameters and immune capacity), meat and carcass traits (15 QTLsanatomy, fatness, meat color and texture), reproductive traits (14 QTLs-litter traits and reproductive organs), exterior traits (7 QTLs-behavioral, defects, conformation, and coat characteristics) and production traits (2 QTLs-bodyweight and days to $100 \mathrm{~kg}$ ) (Table S2 in Supplementary Materials). In these areas, 17 genes were identified (Table 1).

Table 1. Identified genes in L_I vs. L_II.

\begin{tabular}{cccc}
\hline Symbol & Full Name & SSC & Location \\
\hline SASH1 & SAM and SH3 domain containing 1 & 1 & $17306364 . .17663117$ \\
NAV2 & Neuron navigator 2 & 2 & $39263939 . .40083539$ \\
DTWD2 & DTW domain containing 2 & $122680254 . .122937002$ \\
SIL1 & SIL1 nucleotide exchange factor & 2 & $140884170 . .141118201$ \\
A2ML1 & Alpha-2-macroglobulin like 1 & 2 & $62603260 . .62648170$ \\
HS6ST3 & Heparan sulfate 6-O-sulfotransferase 3 & 5 & $65516180 . .66193410$ \\
MBNL2 & muscle blind-like splicing regulator 2 & 11 & $66481923 . .66641653$ \\
MSI2 & Musashi RNA binding protein 2 & 11 & $33537163 . .33974845$ \\
ROBO2 & Roundabout guidance receptor 2 & 12 & $177365712 . .179040027$ \\
RIMP2 & RIMS binding protein 2 & 13 & $24394793 . .24722237$ \\
MSI1 & Musashi RNA binding protein 1 & 14 & $40331371 . .40356793$ \\
SVOP & SV2 related protein & 14 & $41829649 . .41931359$ \\
SART3 & Spliceosome associated factor 3, U4/U6 recycling protein & 14 & $42223752 . .42259992$ \\
SGSM1 & Small G protein signaling modulator 1 & 14 & $42882101 . .42974755$ \\
CDH23 & Cadherin related 23 & 14 & $74267547 . .74734623$ \\
PID1 & Phosphotyrosine interaction domain containing 1 & 15 & $130080821 . .130215548$ \\
DNER & Delta/notch-like EGF repeat containing & 15 & $130414159 . .130754043$ \\
\hline
\end{tabular}

On the basis of the enrichment analysis, we identified two main pathways. The first was the cadherin signaling pathway ( $p$-value $=8.95 \times 10^{-2}$ ), which is involved in many biological processes such as development, neurogenesis, cell adhesion, and inflammation. The second was the Wnt signaling pathway ( $p$-value $=1.88 \times 10^{-1}$ ), which is one of the intracellular signaling pathways for animals that regulates embryogenesis, cell differentiation, and the development of malignant tumors.

In total, 32 SNPs were identified in the genome region with strong outliers in D_I vs. D_II pigs (Table S3 in Supplementary Materials). These areas overlapped with 49 QTLs. Similar to Landrace, we distinguished QTLs for meat and carcass trait: 32 QTLs, 21 of which were associated with fatness (intramuscular fat content); reproductive traits (7 QTLs- 
litter traits and reproductive organs), Health traits (5 QTLs-blood parameters and disease susceptibility), production traits (3 QTLs-growth and feed intake), and exterior traits (2 QTLs-conformation) (Table S4 in Supplementary Materials). In these regions, we identified 14 genes (Table 2).

Table 2. Identified genes in D_I vs. D_II.

\begin{tabular}{cccc}
\hline Symbol & Full Name & SSC & Location \\
\hline RBFOX1 & RNA binding fox-1 homolog 1 & 3 & $34938703 . .37209772$ \\
A2ML1 & Alpha-2-macroglobulin like 1 & $62603260 . .62648170$ \\
NUMB & NUMB endocytic adaptor protein & 5 & $96624270 . .96798690$ \\
KCNK2 & Potassium two pore domain channel subfamily K member 2 & 9 & $128429232 . .128659662$ \\
DTL & Denticleless E3 ubiquitin protein ligase homolog & 9 & $131225840 . .131275426$ \\
FLT1 & FMs-related receptor tyrosine kinase 1 & 11 & $5620698 . .5797095$ \\
MSI2 & Musashi RNA binding protein 2 & 12 & $33537163 . .33974845$ \\
ZNF385 & Zinc finger protein 385D & 13 & $8234734 . .9214628$ \\
SCN10A & Sodium voltage-gated channel alpha subunit 10 & 13 & $23481537 . .23570454$ \\
SCN11A & Sodium voltage-gated channel alpha subunit 11 & 13 & $23602378 . .23692281$ \\
WDR48 & WD repeat domain 48 & 13 & $23735566 . .23786312$ \\
TTC21A & Tetratricopeptide repeat domain 21A & 13 & $23797518 . .23830334$ \\
ROBO2 & Roundabout guidance receptor 2 & 13 & $177365712 . .179040027$ \\
MYO10 & Myosin X & 16 & $5907111 . .6145485$ \\
\hline
\end{tabular}

(SSC-Sus scrofa chromosome).

On the basis of the enrichment analysis, two pathways were identified. The first was the notch signaling pathway $(\mathrm{NUMB})\left(p\right.$-value $\left.=2.55 \times 10^{-2}\right)$, which provides local intercellular communication and coordinates the signaling cascade. Moreover, it plays a certain role in embryogenesis and somitogenesis. The second was the nicotinic acetylcholine receptor signaling pathway $\left(p\right.$-value $\left.=5.81 \times 10^{-2}\right)$, which participates in two main types of neurotransmission: synaptic (e.g., neurotransmitter release) and paracrine transmission.

Overall, 31 genes were identified in the genome region with strong outliers (17 genes in Landrace pigs and 14 genes in Duroc pigs). The A2ML1 (SSC5), ROBO2 (SSC13), and MSI1 (SSC14) genes manifested in both the Landrace and Duroc groups.

\section{Discussion}

Capped hock does not affect the welfare of pigs, but it does damage farming in terms of the sales of pedigree animals. The emergence and spread of capped hock is associated with changes in keeping technology, specifically with the type of floors [2]. There is little data that investigates the prevalence of capped hock in pig farms, but the available data proves that it does not exceed $20 \%[1,6,15]$.

Here, we conducted pilot studies to identify genomic loci and candidate genes that might be linked to the capped hock. The identified regions overlapped with QTLs loci, which is related with meat and carcass traits. Landrace pigs exhibited the most intramuscular fat content in this category. Intramuscular fat content is associated with higher nutritional qualities of pork, and therefore this trait is relevant for selection [16]. One of the factors that influences lipid accumulation and fatty acid composition is adipogenetic capacity [17]. In general, adipose tissue plays a key role in various metabolic processes and affects food intake, inflammatory response, and the meat and reproductive performance in pigs $[18,19]$. Therefore, lipid and fatty acid composition have a direct or indirect relationship with capped hock. Our results show that the identified regions also overlapped with QTLs responsible for health traits and mainly blood parameters. This may indicate that a predisposition to capped hock can be realized through genetic variants associated with hematological signs (concentration and content of corpuscular hemoglobin, platelet count), liver function (bilirubin concentration), kidneys (serum urea level), and susceptibility to the PRRS virus. 
Among the identified genes, A2ML1 (SSC5), which encodes the protein of the alphamacroglobulin superfamily, was identified in Landrace and Duroc pigs. The protein represents an $\mathrm{N}$-glycosylated monomeric protein that behaves as an inhibitor of several proteases. These proteins display a unique trapping inhibition mechanism. Mutations in the A2ML1 gene cause the Noonan-like syndrome with a different phenotype ranging from severe (leading to intrauterine fetal death) to mild [20], as well as some cases of otitis media [21]

$\mathrm{ROBO} 2$ (SSC13) was also identified in the two groups. The $\mathrm{ROBO} 2$ gene encodes a transmembrane receptor and is a member of the immunoglobulin superfamily [22]. Four Robo homologs have been identified in mammals: Robo1 (Dutt1), Robo2, Robo3 (Rig1), and Robo4 (magic roundabout). ROBO receptor expression is crucial for axon control, cell migration, and SLIT/ROBO signaling [23]. The SLIT/ROBO complex is involved in regulating the central nervous system and is involved in lung, kidney, and heart development [24-26]. In addition, the SLIT/ROBO signals affect the respiratory, reproductive, immune, and circulatory systems [27]. Several studies have shown that $\mathrm{ROBO} 2$ gene variants are associated with immunity traits in chickens [27]. Whole-genome association studies of hematological and clinical/biochemical blood traits in large white pigs have identified a number of genes, one of which was ROBO2. It therein showed an association with hemoglobin [28]. Overall, based on our functional characterization and literature data, we determined that genetic variants of the $\mathrm{ROBO} 2$ gene may be associated with the capped hock phenotype in pigs.

The MSI1 (SSC14) and MSI2 (SSC12) genes are extremely interesting. The MSI2 gene is found both in Landrace and Duroc pigs, and the MSI1 gene is found only in Landrace pigs. These genes belong to a unique family of RNA-binding proteins (Musashi family) and are involved in RNA metabolism [29]. In addition, proteins of the Musashi family are considered to perform important functions in the nervous system, as well as hematopoietic systems and systems in the gastrointestinal tract (e.g., neural, hematopoietic, and gastrointestinal) in various species [30-32]. MSI1 functions as a regulator to maintain stem cell condition, differentiation, and tumorigenesis [33]. Excessive expression of MSI1 leads to cell proliferation and apoptosis [34]. In addition, MSI1 is associated with many malignant neoplasms in humans [35]. Many studies have recently sought to determine the molecular basis of MSI2 activity and its physiological manifestations. According to Bennett et al. [32], MSI2 is a regulator of keratinocyte migration and epithelial growth. It is also involved in regulating focal adhesion and apoptosis.

Dysregulation of adhesion molecules often leads to various diseases, including inflammation [36,37]. Cadherins play an important role in regulating adhesion because they are calcium-dependent glycoproteins. Our studies identified the $\mathrm{CDH} 23$ gene (cadherin 23) and the cadherin signaling pathway in Landrace pigs. In addition to the formation of strong intercellular contacts, cadherins initiate various intracellular signaling cascades and may be associated with tumor progression and inflammatory arthritis in humans [38].

Moreover, MSI showed transducing MSI/NUMB/Notch signals (Notch signaling pathway). Our studies also identified the NUMB gene (NUMB endocytic adapter protein, SSC7) and the Notch signaling pathway in Duroc pigs. Notch signaling is evolutionarily conservative and is critical during the development and homeostasis of mature tissues by regulating cell proliferation, differentiation, and cell apoptosis. In addition, the interaction of MSI/NUMB/Notch is considered to be associated with many malignant neoplasms in humans [39].

The research results showed 70 SNPs associated with the capped hock in Landrace (38 SNPs) and Duroc (32 SNPs), as well as 31 genes involved in various physiological processes in the body, including those related with inflammation, the formation of various neoplasms, and tumors. However, further research is needed to confirm the obtained results, especially research that examines other breeds and populations. The use of various methods, including the genome-wide association study, will contribute to the identification 
of genomic regions and candidate genes associated with capped hock, which will thus promote the production of highly productive pigs free from various defects.

\section{Conclusions}

Here, pilot studies aimed at searching for genomic loci and candidate genes linked to the capped hock in Landrace and Duroc pigs were carried out. The identified genes are involved in various physiological processes in the organism. However, it is interesting to note that the identified regions overlap with QTLs related with health traits (blood parameters), as well as in meat and carcass traits (Fatness). This may indicate that the predisposition to the capped hock can be realized through genetic variants related with composition of lipids and fatty acids, as well as in hematological traits and susceptibility to disease.

Supplementary Materials: The following are available online at https:/ / www.mdpi.com/article/ 10.3390/life11060510/s1, Table S1: SNPs with the most significant signals in L_I vs. L_II, Table S2: QTLs, determined in L_I vs. L_II, Table S3: SNPs with the most significant signals in D_I vs. D_II, Table S4: QTLs, determined in D_I vs. D_II.

Author Contributions: Conceptualization, L.G. and S.B.; methodology, L.G. and S.B.; software, F.B. and S.B.; validation, L.G., F.B., and S.B.; formal analysis, S.B.; investigation, L.G., F.B., M.K., A.Z., and S.B.; data curation, F.B. and S.B.; writing-original draft preparation, L.G. and M.K.; writing-review and editing, L.G., S.B., and M.K. All authors have read and agreed to the published version of the manuscript.

Funding: This research was funded by Russian Foundation for Basic Research 19-016-00068 A (the study of pigs with capped hock) and Russian Science Foundation within Project No. 19-76-10012 (the study of pigs without capped hock).

Institutional Review Board Statement: Not applicable.

Informed Consent Statement: Not applicable.

Data Availability Statement: The raw data supporting the conclusions of this article will be made available by the authors upon reasonable request.

Conflicts of Interest: The authors declare that the research was conducted in the absence of any commercial or financial relationships that could be construed as a potential conflict of interest.

\section{References}

1. Ostner, F.; Hergt, T.; Klein, S.; Patzkéwitsch, D.; Reese, S.; Brühschwein, A.; Meyer-Lindenberg, A.; Schade, B.; Böhm, B.; Eisenreich, R.; et al. Technopathien der Gliedmaßen bei Mastschweinen: Ursachen, Entstehung, Tierschutzrelevanz [Technopathies of the limbs in finishing pigs: Risk factors, origin and impact on animal welfare-Study phase 1]. Tierarztl. Prax. Ausg. G Grosstiere Nutztiere 2018, 46, 307-315.

2. Hergt, T.; Ostner, F.; Klein, S.; Zöls, S.; Erhard, M.; Reese, S.; Ritzmann, M.; Patzkéwitsch, D. Technopathien der Gliedmaßen bei Mastschweinen: Ursa chen, Entstehung und Tierschutzrelevanz [Technopathies of the limbs in finishing pigs: Risk factors, origin and impact on animal welfare-Study phase 2]. Tierarztl. Prax. Ausg. G Grosstiere Nutztiere. 2018, 46, 368-377.

3. Bakoev, S.; Getmantseva, L.; Kolosova, M.; Kostyunina, O.; Chartier, D.R.; Tatarinova, T.V. PigLeg: Prediction of swine phenotype using machine learning. PeerJ 2020, 8, e8764. [CrossRef]

4. Le, T.H.; Christensen, O.F.; Nielsen, B.; Sahana, G. Genome-wide association study for conformation traits in three Danish pig breeds. Genet. Sel. Evol. 2017, 49, 1-12. [CrossRef]

5. Van Son, M.; Andersen-Ranberg, I.M.; Lopes, M.S.; Hamland, H.; Grindflek, E. Genome-wide association study and fine mapping of a QTL on SSC13 for Osteochondrosis in Duroc pigs. In Proceedings of the World Congress on Genetics Applied to Livestock Production, Electronic Poster Session: Aotea Centre, Auckland, New Zealand, 11-16 February 2018; Volume 1, p. 276.

6. Gillman, C.E.; Kilbride, A.L.; Green, L.E. Prevalence of bursitis and capped hock in weaner to finisher pigs and risks associated with flooring factors: A cross-sectional study of 103 GB pig farms. In Proceedings of the ISVEE 11: 11th Symposium of the International Society for Veterinary Epidemiology and Economics, Theme 2-Disease Distribution \& Determinants: Pigs Session, Cairns, Australia, 6-11 August 2006; p. 495.

7. Meyer-Hamme, S.; Lambertz, C.; Gauly, M. Does group size have an impact on welfare indicators in fattening pigs? Animal 2016, 10, 142-149. [CrossRef]

8. Teixeira, D.L.; Salazar, L.C.; Enriquez-Hidalgo, D.; Boyle, L.A. Assessment of Animal-Based Pig Welfare Outcomes on Farm and at the Abattoir: A Case Study. Front. Vet. Sci. 2020, 7, 576942. [CrossRef] [PubMed] 
9. Gurgul, A.; Jasielczuk, I.; Ropka-Molik, K.; Semik-Gurgul, E.; Pawlina-Tyszko, K.; Szmatoła, T.; Szyndler-Nędza, M.; BugnoPoniewierska, M.; Blicharski, T.; Szulc, K.; et al. A genome-wide detection of selection signatures in conserved and commercial pig breeds maintained in Poland. BMC Genet. 2018, 19, 1-17. [CrossRef] [PubMed]

10. De Simoni Gouveia, J.J.; Da Silva, M.V.G.; Paiva, S.R.; De Oliveira, S.M.P. Identification of selection signatures in livestock species. Genet. Mol. Biol. 2014, 37, 330-342. [CrossRef] [PubMed]

11. Kunhareang, S.; Zhou, H.; Hickford, J. Rapid DNA extraction of pig ear tissues. Meat Sci. 2010, 85, 589-590. [CrossRef]

12. Barker, V.A.; Blackford, L.S.; Dongarra, J.; Du Croz, J.; Hammarling, S.; Marinova, M.; Waśniewski, J.; Yalamov, P. LAPACK95 Users' Guide; Society for Industrial \& Applied Mathematics (SIAM): Philadelphia, PA, USA, 2001.

13. VanRaden, P.M. Efficient Methods to Compute Genomic Predictions. J. Dairy Sci. 2008, 91, 4414-4423. [CrossRef] [PubMed]

14. Nicholson, G.; Smith, A.V.; Jonsson, F.; Gustafsson, O.; Stefansson, K.; Donnelly, P. Assessing population differentiation and isolation from single-nucleotide polymorphism data. J. R. Stat. Soc. Ser. B Stat. Methodol. 2002, 64, 695-715. [CrossRef]

15. Kilbride, A.; Gillman, C.; Ossent, P.; Green, L. A cross-sectional study of the prevalence and associated risk factors for capped hock and the associations with bursitis in weaner, grower and finisher pigs from 93 commercial farms in England. Prev. Vet. Med. 2008, 83, 272-284. [CrossRef]

16. Ren, Z.; Wang, Y.; Ren, Y.; Zhang, Z.; Gu, W.; Wu, Z.; Chen, L.; Mou, L.; Li, R.; Yang, H.; et al. Enhancement of porcine intramuscular fat content by overexpression of the cytosolic form of phosphoenolpyruvate carboxykinase in skeletal muscle. Sci. Rep. 2017, 7, srep43746. [CrossRef]

17. Piedrafita, J.; Christian, L.L.; Lonergan, S.M. Fatty acid profiles in three stress genotypes of swine and relationship with performance, carcass and meat quality traits. Meat Sci. 2001, 57, 71-77. [CrossRef]

18. Getmantseva, L.; Kolosov, A.; Leonova, M.; Bakoev, S.; Klimenko, A.; Usatov, A.; Radyuk, A.; Vaselenko, V.; Makarenko, M.; Bakoev, N. Polymorphism in obesity—related leptin gene and its association with reproductive traits of sows. Bulg. J. Agric. Sci. 2017, 23, 848-855.

19. Poklukar, K.; Čandek-Potokar, M.; Lukač, N.B.; Tomažin, U.; Škrlep, M. Lipid Deposition and Metabolism in Local and Modern Pig Breeds: A Review. Animal 2020, 10, 424. [CrossRef] [PubMed]

20. Vissers, L.E.L.M.; Bonetti, M.; Overman, J.P.; Nillesen, W.M.; Frints, S.G.M.; de Ligt, J.; Zampino, G.; Justino, A.; Machado, J.C.; Schepens, M.; et al. Heterozygous germline mutations in A2ML1 are associated with a disorder clinically related to Noonan syndrome. Eur. J. Hum. Genet. 2014, 23, 317-324. [CrossRef] [PubMed]

21. Larson, E.D.; Magno, J.P.M.; Steritz, M.J.; Llanes, E.G.D.; Cardwell, J.; Pedro, M.; Roberts, T.B.; Einarsdottir, E.; Rosanes, R.A.Q.; Greenlee, C.; et al. A2ML1and otitis media: Novel variants, differential expression, and relevant pathways. Hum. Mutat. 2019, 40, 1156-1171. [CrossRef]

22. Kidd, T.; Brose, K.; Mitchell, K.J.; Fetter, R.D.; Tessier-Lavigne, M.; Goodman, C.S.; Tear, G. Roundabout Controls Axon Crossing of the CNS Midline and Defines a Novel Subfamily of Evolutionarily Conserved Guidance Receptors. Cell 1998, 92, 205-215. [CrossRef]

23. Long, H.; Sabatier, C.; Ma, L.; Plump, A.; Yuan, W.; Ornitz, D.M.; Tamada, A.; Murakami, F.; Goodman, C.S.; Tessier-Lavigne, M. Conserved Roles for Slit and Robo Proteins in Midline Commissural Axon Guidance. Neuron 2004, 42, 213-223. [CrossRef]

24. Grieshammer, U.; Ma, L.; Plump, A.S.; Wang, F.; Tessier-Lavigne, M.; Martin, G.R. SLIT2-Mediated ROBO2 Signaling Restricts Kidney Induction to a Single Site. Dev. Cell 2004, 6, 709-717. [CrossRef]

25. Greenberg, J.M.; Thompson, F.Y.; Brooks, S.K.; Shannon, J.M.; Akeson, A.L. Slit and robo expression in the developing mouse lung. Dev. Dyn. 2004, 230, 350-360. [CrossRef]

26. Prasad, A.; Paruchuri, V.; Preet, A.; Latif, F.; Ganju, R.K. Slit-2 induces a tumor suppressive effect by regulating beta-catenin in breast cancer cells. J. Biol. Chem. 2008, 283, 26624-26633. [CrossRef] [PubMed]

27. Wang, Y.; Wang, J.; Li, B.H.; Qu, H.; Luo, C.L.; Shu, D.M. An association between genetic variation in the roundabout, axon guidance receptor, homolog 2 gene and immunity traits in chickens. Poult. Sci. 2014, 93, 31-38. [CrossRef] [PubMed]

28. Bovo, S.; Mazzoni, G.; Bertolini, F.; Schiavo, G.; Galimberti, G.; Gallo, M.; Dall'Olio, S.; Fontanesi, L. Genome-wide association studies for 30 haematological and blood clinical-biochemical traits in Large White pigs reveal genomic regions affecting intermediate phenotypes. Sci. Rep. 2019, 9, 1-17. [CrossRef]

29. Sakakibara, S.-I.; Nakamura, Y.; Satoh, H.; Okano, H. RNA-Binding Protein Musashi2: Developmentally Regulated Expression in Neural Precursor Cells and Subpopulations of Neurons in Mammalian CNS. J. Neurosci. 2001, 21, 8091-8107. [CrossRef]

30. Ito, T.; Kwon, H.Y.; Zimdahl, B.; Congdon, K.L.; Blum, J.; Lento, W.E.; Zhao, C.; Lagoo, A.; Gerrard, G.; Foroni, L.; et al. Regulation of myeloid leukaemia by the cell-fate determinant Musashi. Nature 2010, 466, 765-768. [CrossRef]

31. Wang, S.; Li, N.; Yousefi, M.; Nakauka-Ddamba, A.; Li, F.; Parada, K.; Rao, S.; Minuesa, G.; Katz, Y.; Gregory, B.D.; et al. Faculty Opinions recommendation of Transformation of the intestinal epithelium by the MSI2 RNA-binding protein. Nat. Commun. 2015, 6, 6517. [CrossRef] [PubMed]

32. Bennett, C.G.; Riemondy, K.; Chapnick, U.A.; Bunker, E.; Liu, X.; Kuersten, S.; Yi, R. Genome-wide analysis of Musashi-2 targets reveals novel functions in governing epithelial cell migration. Nucleic Acids Res. 2016, 44, 3788-3800. [CrossRef]

33. Okano, H. Stem cell biology of the central nervous system. J. Neurosci. Res. 2002, 69, 698-707. [CrossRef]

34. Battelli, C.; Nikopoulos, G.N.; Mitchell, J.G.; Verdi, J.M. The RNA-binding protein Musashi-1 regulates neural development through the translational repression of p21WAF-1. Mol. Cell Neurosci. 2006, 31, 85-96. [CrossRef] [PubMed] 
35. Forouzanfar, M.; Lachinani, L.; Dormiani, K.; Nasr-Esfahani, M.H.; Gure, A.O.; Ghaedi, K. Intracellular functions of RNA-binding protein, Musashi1, in stem and cancer cells. Stem Cell Res. Ther. 2020, 11, 1-10. [CrossRef]

36. Becker, S.F.; Langhe, R.; Huang, C.; Wedlich, R.; Kashef, J. Giving the right tug for migration: Cadherins in tissue movements. Arch. Biochem. Biophys. 2012, 524, 30-42. [CrossRef]

37. Langhe, R.P.; Gudzenko, T.; Bachmann, M.; Becker, S.F.; Gonnermann, C.; Winter, C.; Abbruzzese, G.; Alfandari, D.; Kratzer, M.-C.; Franz, C.M.; et al. Cadherin-11 localizes to focal adhesions and promotes cell-substrate adhesion. Nat. Commun. 2016, 7, 10909. [CrossRef] [PubMed]

38. Ding, X.; Zhang, Y.; Huang, Y.; Liu, S.; Lü, H.; Sun, T. Cadherin-11 involves in synovitis and increases the migratory and invasive capacity of fibroblast-like synoviocytes of osteoarthritis. Int. Immunopharmacol. 2015, 26, 153-161. [CrossRef]

39. Okano, H.; Kawahara, H.; Toriya, M.; Nakao, K.; Shibata, S.; Imai, T. Function of RNA-binding protein Musashi-1 in stem cells. Exp. Cell Res. 2005, 306, 349-356. [CrossRef] [PubMed] 